\title{
Motivation to Study English Among Chinese Visiting Scholars
}

\author{
Lucy K. Spence ${ }^{1}$, Haiying Wang ${ }^{2, ~ *, ~ X u m e i ~}$ Fan $^{1}$ \\ ${ }^{1}$ College of Education, University of South Carolina, Columbia, USA \\ ${ }^{2}$ Ideological and Political Department, Shanxi Polytechnic College, Taiyuan City, China
}

Email address:

spence2@email.sc.edu (L. K. Spence), why751024@163.com (Haiying Wang), fan9@email.sc.edu (Xumei Fan)

${ }^{*}$ Corresponding author

\section{To cite this article:}

Lucy K. Spence, Haiying Wang, Xumei Fan. Motivation to Study English Among Chinese Visiting Scholars. International Journal of Education, Culture and Society. Vol. 6, No. 3, 2021, pp. 71-78. doi: 10.11648/j.ijecs.20210603.11

Received: April 16, 2021; Accepted: April 30, 2021; Published: May 14, 2021

\begin{abstract}
Self Determination Theory (SDT) offers a multifaceted perspective of human motivation to foresee specific behavioral outcomes. It affords an understanding of human motivation. However, most researches on motivation have been applied to educational contexts of school-aged groups and graduate students in tertiary education. Little motivational research has explored Chinese visiting scholars in the context of adult education. In the study reported here, a questionnaire is designed to measure the relationship between different demographic variables and motivation types and the reasons behind those motivations in the context of the target language, English. The purpose of this study is to provide an empirical foundation concerning Chinese visiting scholars' various study motivations after they obtained language qualification and a solid language base in China. The results indicate that respondents are motivated by an autonomous level of self-determination due to a desire to communicate in English with their colleagues and within their field of study. Some respondents are also motivated by social and cultural considerations.
\end{abstract}

Keywords: Self-determination Theory, Chinese Visiting Scholars, Extra-curricular Oral English Study

\section{Introduction}

With the rapid development of the economy, science and technology in China, more and more Chinese visiting scholars have been sent to western countries such as the United States, Britain, Germany, and France, among others, for scholarly visits [1]. This trend reflects a growing internationalism in advanced education worldwide. Chinese visiting scholars, as an important element of international knowledge in a time of globalization, mainly consist of professors and researchers. They are carriers of knowledge across borders and the embodiment of a cosmopolitan scientific culture [2]. From a national macro- perspective, the overseas scholarly visiting experience is undoubtedly a rare opportunity to enhance collaboration and communication between China and other countries in the fields of education, science, and technology by learning and communicating with native professors. From a micro-perspective, it strengthens Chinese visiting scholars' confidence in sharpening their
English language skills in an authentic language context. In addition, it increases their understanding of the host culture, broadens their worldview and of particular importance, increases professional competence in the long run.

Before going abroad, Chinese visiting scholars are evaluated on their eligibility and qualifications in English language proficiency and work experience by different Chinese scholarship councils. After receiving permission, they typically sojourn in the host country for three months to one year to pursue non-degree study abroad. In general, their oral English level is above average. However, compared to native speakers, Chinese visiting scholars are still developing oral English, especially in the aspects of fluency, control of idioms, and understanding of cultural pragmatics.

As a result of Chinese visiting scholars' increasing presence in recent years, more attention is being paid to this vital academic socialization in international exchange. Chinese visiting scholars, as a special category are under-represented in academic motivation research [3]. Very little is known about motivation leading to Chinese visiting scholars continuing 
English development in the target context, specifically quantitative motivation research investigating extra-curricular oral English study. Because of the Chinese visiting scholar's special academic identity and learning preferences, their motivation for continuing English study is worth examining.

In second language learning, the issue of motivation has been argued as a basic mechanism that propels learners forward. Robert Gardner was one of the first social psychologists to study motivation in second language learning. He engaged in multiple studies of motivation in Canada in a Fracophone and Anglephone setting. The most developed aspect of Gardner's research was integrativeness, including "the combination of effort plus desire to achieve the goal of the language, plus favorable attitudes toward learning the language". Motivation research has since taken a cognitive turn, including self-determination theory [4]. Two main terms associated with this theory are intrinsic and extrinsic motivation. Self- determination theory lends itself to this study of Chinese visiting scholars' motivation to study English.

The present investigation, centered in self-determination theory (SDT), explores the motivations that stimulate interest and initiative to participate in extra-curricular oral English study among Chinese academics who have already obtained language qualification in China. Specifically, the study examines if extrinsic motivation, in contrast to intrinsic motivation, may be involved. The present study examines Chinese visiting scholars' intrinsic and extrinsic motivation levels and degree that undergird their reasons for learning oral English. Hence, this model has potential for empirical applications for a special group of adults who represent unique characteristic. Five research questions guided the study:

1) Which aspects of motivation stimulate greater interest to study oral English?

2) What are Chinese visiting scholars' intrinsic and extrinsic motivations based on their gender, major, age, academic degree, and professional rank?

3) What are the relationships between the Chinese visiting scholars' motivations based on their gender, major, age, academic degree, and professional rank?

4) Do the Chinese visiting scholars perceive the extracurricular experience as strengthening and extending the participants' personal and professional oral English proficiency?

5) What are the demographic variables that could predict Chinese visiting scholars' overall motivation of attending extra-curricular oral English study?

\section{Literature Review}

\subsection{Self-Determination Theory}

Self-determination theory (SDT) is a relatively complete theoretical framework that concerns the function of personality and human development in different contexts [5]. The focus of the theory is the interplay between the extrinsic forces influencing people and the intrinsic motives and needs inherent in human nature. The theory suggests that human motivation derives from the satisfaction of basic psychological needs. Projected into specifically foreign language study, motivation reflects an attitude toward language learning and the extent to which the individual works or strives to learn oral English because of a desire to do so and the satisfaction experienced in this activity. In other words, it determines the extent of active personal involvement.

In general, motivated individuals can be either intrinsically or extrinsically motivated.

Intrinsic motivation involves seeking challenges that are neither too easy nor too difficult and attempting to conquer the challenges. Extrinsic motivation can be either controlled by outside influences or genuinely chosen by the individual. When the latter is the case, the behavior would be more selfdetermined[6]. Ryan and Deci claimed that learners who initially have no motivation to act can be motivated.

Ryan and Deci described intrinsic motivation in terms of doing something for the sheer fun, performing of an activity for its inner satisfaction based on psychological needs without thought of the subsequent instrumental value of the activity. Intrinsic motivation occurs when people are involved in activities that are novel, challenging, or hold aesthetic interest.

Activities that are chosen out of interest or a sense of stimulation and that produce satisfaction are intrinsically motivated. Self-determination is integral to intrinsic motivation.

Self-determination can also be found in some extrinsically motivated behavior when the behavior involves choice, rather than drives such as hunger or fear. Extrinsic motivation can involve self-determination when the person behaves according to their own choice. A person may choose to have control over an outcome, or choose to allow others to have control. However, it is the exercising of choice that points to self-determination. Conversely, extrinsic motivation often does not involve choice. Deci and Ryan have identified four different types of extrinsic motivation that fall along a continuum ranging from very low to very high levels of selfdetermination within SDT: external regulation, introjected regulation, identified regulation and integrated regulation in increasing order of internalization.

External regulation is not self-determined. It involves salience of extrinsic rewards or punishments. It is simply a tool and the lowest level of autonomy with which to satisfy one's actual needs. In the context of the academic sector, it stems from the desire to satisfy directly one's non-academicrelated needs such as obtaining employment or a high salary in the future. Introjected regulation represents a more internalized degree compared to external regulation. In the stage of introjected regulation, people perform an activity that is more internalized because of certain kind of pressure, a sense of guilt or self-aggrandizement. Dörnyei and Ushioda found from Chinese students' questionnaires that the students felt great pressure in their aspiration to gain promotion or felt a great obligation to study to secure a higher salary to support a family. They engaged in academic study in order to reduce guilt or pressure. Even though they may not be intrinsically motivated, they chose to study. The next stage of 
internalization is identified as introjected regulation. At this point, the individual decides to perform a behavior because he or she reviews the activity as personally worthwhile. It is more autonomous and self-determined, but is still extrinsic in nature because the behavior is conducted to accomplish an end rather for the activity itself. Finally, integrated regulation involves behavior that is thoroughly incorporated with a person's self and value system.

Besides intrinsic and extrinsic motivation, amotivation is a third type of motivational construct. It means individuals perceive their behaviors as caused by forces out of their own control. They do not engage in either intrinsically or extrinsically motivated behavior. In the current study, the Chinese visiting scholars voluntarily attend extra-curricular oral English learning, strongly suggesting they are motivated from either intrinsic or extrinsic motivation. Therefore, this study focused on examining the Chinese visiting scholars' intrinsic and extrinsic motivation.

\subsection{Mutual Effect Between Intrinsic and Extrinsic Motivation}

The distinction and relation between intrinsic and extrinsic types of motivation have shed important light on both developmental and educational practices. Gulbinskienè and Dubovičiene claimed that language learners should be motivated less by extrinsic factors and more by intrinsic ones, because too much extrinsic motivation would make students reluctant to take up new learning challenges at university[7]. Morgan found that some positive elements, such as praise or rewards related to competent performance promoted intrinsic motivation, whereas external control elements such as unpleasant associations, sanctions and pressure would thwart intrinsic behaviors. One study demonstrated that extrinsic incentives propelled intrinsic motivation and creativity when it made the task more interesting or challenging. Other researchers indicated that extrinsic motivation does not necessarily undermine intrinsic motivation, especially when students have low levels of intrinsic motivation, it may even enhance it. According to Kember, extrinsic motivation could be explained as a positive form of motivation. It not only co- exists with intrinsic motivation, but also can positively intensify it[8]. Kember, Hong, and Ho describe a dynamic framework for motivation in which various facets of motivation influence other facets. In this view, motivation is not seen as bipolar; either extrinsic or intrinsic, but that both types of motivation can coexist.

Since motivation research about Chinese visiting scholars is sparse, this study adds to the literature on foreign language motivation of international adult learners in a target language context and specifically, Chinese learners in the English language context.

\subsection{English Study Motivation Constructs of International Learners}

Second language learning motivation has been studied for over 60 years, beginning with Robert Gardner's studies in the bilingual Canadian context. Gardner described a motivated learner as eager to learn the language, willing to expend effort on the learning activity, and willing to sustain the learning activity. For example, if a student is positively motivated to study, then he or she will study more initiatively and actively. Crookes and Schmidt suggested a broad definition of second language learning motivation in the pedagogical context. They illustrate that motivation to learn a language has both internal and external features and these two features can transform each other. Looking forward to trends in language motivation research, Al-Hoorie reviewed the literature on language learning motivation. This review explained the social-psychological and situated cognitive theories of motivation, then provided an overview of current trends such as affect and emotion, unconscious motivation, long-term motivation, motivation to learn languages other than English, and technology as motivation [9].

The motivation of adults to learn is obviously different compared to traditional-age students [10]. Adult learners must be motivated to enhance and refine each aspect of global competence and to speak and act appropriately. Kormos and Csizér compared language learning motivation among secondary students, university students and adults and concluded that the ideal self is a very important factor among the adult and university students because they have formed a self-image and fit into their social group easily. Focusing on attitudes, Weger studied motivation in adults ages 18-60 in an International English Program [11]. Participants from 31 countries, with a large number from South Korea were surveyed. Weger found that the participants were motivated less by positive attitudes toward the English community, and more motivated by personal accomplishment in learning English. Ehrman and Oxford examined adult language learning strategies and reported the relationships between demographic variables such as sex, career choice, and psychological type. They concluded that gender and occupation have a real effect on language level and personality factors regarding choice of learning strategies. Within the field of foreign language learning and teaching, Shumin found that cultivating speaking ability was difficult for EFL learners, especially adults, in terms of fluency and appropriate use. Thus, the ideal self, personal accomplishment, choice of learning strategies, and cultivating speaking ability are all topics that have been explored in terms of motivation. These studies provide insights into adult motivation to learn English, however little research specifically examines Chinese visiting scholars' extra- curricular oral English study motivation.

\subsection{Motivation Constructs for Oral English Study Among Chinese in the USA}

For many Chinese visiting scholars, previous exposure to English was in the classroom. Therefore, although they could pass certain English exams, they may not feel comfortable with conversing in English. For this reason, once they arrive in an English language context, participating in language learning activities is considered an indispensable opportunity 
and pathway to reach academic attainment and their academic exchange goal. They especially hope to continually study oral English to enhance communication with their mentors or to continue their inclination to speak English. These two desires are strongly linked in Chinese visiting scholars' minds compared to other reasons such as making friends, travelling, immigration or self-esteem.

Studies of university students provide some background on English language experiences among Chinese in the USA. Yuan asserted that Chinese overseas students fail to have much interaction with Americans mainly due to their limited English and cultural differences [12]. Wang and Zuo noted that English proficiency is the biggest challenge for Chinese doctoral students[13]. Yet, Hernandez clarified that the study-abroad context plays a momentous role in enhancing students' oral proficiency. Yashima found that going abroad for work and forming a healthy awareness toward the target language culture is closely related to the language learner's ideal self.

Chinese adults living outside the university experience in the USA are also motivated to continually learn English. Larrota argued that language intensive training provides immigrant adult learners with the means by which they forge relationships with neighbors [14], colleagues at work, and the people who work in the shops, agencies, and institutions in their new country. Because this adult oral English programs emphasizes short-term goals such as adjusting to the host society very quickly or to bridge the basic survival in the target situation, the instructional orientation often targets low-literacy adults. Those who choose to attend non-profit community-based ESL services for intercultural mixing often are less educated or unable to speak perfect English. Some non-profit, community-based ESL services are church based.

Church-based programs may influence language effects. As Punetha, Giles, and Young argued, ideology from church will gradually affect participants' study orientations. David Smith and Barbara Carvell explored the connections between faith and foreign language learning in a context of simultaneously increasing globalization and deepening pluralism.

Chinese visiting scholars tend to adjust their learning preferences to fit in the target language environment after gaining entry to the USA. They normally choose to accept a type of volunteer-based one-to-one tutoring or small-group learning model within local community- based ESL services agencies or church-based ESL programs. These language learning situations offer learners greater access as a tool for exchanging information and participating in social and international functions. These classes are very comfortable and non-threatening because of the relaxed learning atmosphere, flexible teaching methods, and authentic teaching materials. In addition, the teaching content among these organizations gives priority to listening and speaking. In brief, these organizations available all over the United States are with the aim of creating a supportive pathway and bridge for the international visitors.

\subsection{Purpose of the Present Study}

This review of literature has not uncovered the relative researches focused on the motivation of Chinese students studying in the USA and Chinese immigrants outside a university setting. Nor research on Chinese visiting scholars' extra-curricular oral English study was found. Hence, based on the various reasons or goals for learning English, the researcher distinguishes different types of motivation by using self-determination theory to address how overall motivation varies and how extrinsic motivation positively influences intrinsic motivation when learning English in the USA. This research provides some insights for educators and organizers to better understand motivation to study English by visiting Chinese scholars in an extra- curricular setting.

\section{Methodology}

This study was based on a two-part survey. The first part consisted of 20 statements. The second part consisted of two open-ended questions dealing with the reasons and the results of attending extra-curricular oral English study. In the first part, items were scored on five-point Likert scale, ranging from Strongly Disagree (1) to Strongly Agree (5). For all items, the higher the value is, the more positive the motivation will be.

\subsection{Instruments}

A commercially available common questionnaire was developed for the specific purpose of this study. Two avenues were used to recruit participants. Firstly through personal contacts with fellow visiting scholars, and secondly through introduction by our colleagues to other visiting scholars. A first draft of the questionnaire was pilot tested (with a small sample of Chinese visiting scholars) for ease of response and administration, and revised where necessary. The final version of the questionnaire was provided to Chinese visiting scholars by email or social chatting platform. The respondents were asked to answer honestly. We designed the survey based on our experience in non-profit communitybased ESL services such as adult oral English classes, international adult English centers and international friendship ministries, and church-based ESL programs in the city we were visiting and other cities in USA. Although we do not claim that our results generalize beyond the context of Chinese visiting scholars, it is hoped that the thesis can serve as a guide for practitioners or organizers to motivate Chinese visiting scholars forward and provide advice for studying oral English outside of the traditional classroom settings.

\subsection{Participants}

In this study, the data consists of 82 sampled questionnaires about oral English learning motivation. Of these, 63\% participants were female and $37 \%$ were male. The age groups mainly divided into four parts which ranged from thirty or younger, thirty-one to forty, forty-one to fifty, and fifty-one or older. The specific context within which we made the survey was in the various adult education programs and church organized, oral English classes all over the United States.

The academic majors of respondents were varied. In order to analyze Chinese visiting scholars' motivation more 
conveniently and objectively, the group surveyed was divided into two subgroups based on the specific professional orientation such as English major or others.

Participants came from different universities in the USA by purposive sampling and snowball sampling. Because all the participants were selected from China, the questionnaire was in Chinese. It was piloted with frequent guests attending oral English classes to check that the instructions were clear and comprehensive. The criteria for sample collection were Chinese visiting scholars who had visited USA and attended extra-curricular oral English classes at least four times when the study began.

All participants completed the survey, a 20-item scale that measured intrinsic and extrinsic motivation. The scale was comprised of six subscales. Nearly half of the subscales measured intrinsic motivation, the rest measured extrinsic motivation. In addition, respondents answered two openended questions: Please describe your major reasons for attending an extra-curricular oral English class. Please briefly describe your oral English gains after attending the extracurricular oral English class.

\subsection{Statistics Analysis}

We conducted descriptive statistics analysis to help understand Chinese visiting scholars' motivation for attending extra-curricular oral English study. As shown in Table 1, Chinese visiting scholars seemed to have strong motivation in three aspects including convenience for overseas travel, communication, and opportunities to socialize. They had weak motivation for immigration to English-speaking countries, financial help, and improving social status. Therefore, these purposes of attending extracurricular oral English study are not their major motivation.

Table 1. Questions about Motivation.

\begin{tabular}{llll}
\hline Questions & N & Mean & $\begin{array}{l}\text { Std. } \\
\text { Deviation }\end{array}$ \\
\hline It is helpful when I travel overseas. & 82 & 4.40 & 0.70 \\
It helps me communicate with others. & 81 & 4.14 & 0.75 \\
It provides me opportunities to socialize. & 82 & 4.02 & 0.83 \\
I want to make international friends. & 82 & 3.89 & 0.80 \\
It increases my confidence. & 82 & 3.85 & 0.96 \\
I am interested in American culture. & 82 & 3.84 & 0.85 \\
It makes me happy. & 82 & 3.82 & 0.77 \\
It benefits me when I compete with others. & 81 & 3.70 & 0.86 \\
I like the process of English learning and & 82 & 3.66 & 1.00 \\
speaking. & & & \\
It provides me opportunities to work with & 82 & 3.63 & 0.95 \\
colleagues. & 82 & 3.50 & 1.07 \\
It can help me with future English tests. & 82 & 3.41 & 1.02 \\
I want to challenge myself. & 82 & 3.39 & 0.99 \\
It is my hobby. & 82 & 3.35 & 1.00 \\
My friends think I can learn English well. & 82 & 3.32 & 1.02 \\
It can help me have a better future. & 82 & 3.18 & 0.92 \\
It can help change my current living condition. & 81 & 3.17 & 0.95 \\
I feel guilty when I cannot speak English well. & 81 & 2.85 & 0.89 \\
It can help improve my social status. & 82 & 2.78 & 0.88 \\
It can help me financially. & 82 & 2.00 \\
I want to immigrate to English-speaking & 81 & 2.38 & 1.00 \\
countries. & & & \\
\hline & & & \\
\hline
\end{tabular}

Besides Chinese visiting scholars' overall motivation, we also explored their intrinsic and extrinsic motivation by taking their demographic information into consideration. Table 2 describes Chinese visiting scholars' intrinsic and extrinsic motivation based on their gender.

Male scholars had more overall motivation than female scholars. Comparatively, female scholars had more intrinsic motivation, and male scholars had more extrinsic motivation.

Table 2. Motivation Differences based on Gender.

\begin{tabular}{lllll}
\hline Motivation & Gender & N & Mean & Std. Deviation \\
\hline Intrinsic Motivation & Male & 30 & 24.33 & 4.40 \\
& Female & 51 & 25.61 & 4.28 \\
Extrinsic Motivation & Male & 28 & 46.71 & 5.73 \\
& Female & 51 & 44.53 & 7.28 \\
Overall Motivation & Male & 28 & 71.14 & 9.01 \\
& Female & 50 & 70.10 & 10.90 \\
\hline
\end{tabular}

Table 3 describes Chinese visiting scholars' intrinsic and extrinsic motivation based on their major. Scholars who were majoring in English and those who were non-English majors had very similar intrinsic motivation. However, non-English major scholars had more extrinsic motivation than the English-major scholars.

Table 3. Motivation Differences based on Major.

\begin{tabular}{lllll}
\hline Motivation & Major & N & Mean & $\begin{array}{l}\text { Std. } \\
\text { Deviation }\end{array}$ \\
\hline Intrinsic Motivation & English Major & 16 & 25.31 & 3.092 \\
& Non-English Major & 65 & 25.09 & 4.612 \\
Extrinsic Motivation & English Major & 17 & 43.88 & 6.314 \\
& Non-English Major & 62 & 45.69 & 6.95 \\
Overall Motivation & English Major & 16 & 69.00 & 8.33 \\
& Non-English Major & 62 & 70.85 & 10.67 \\
\hline
\end{tabular}

Table 4 shows Chinese visiting scholars' intrinsic and extrinsic motivation based on their age. It appeared that younger scholars tended to have more intrinsic and extrinsic motivation. The age of 30 seemed to make a difference for their motivation for attending extra-curricular oral English study. However, we should notice that there are only five respondents in this category.

Table 4. Motivation Differences based on Age.

\begin{tabular}{lllll}
\hline & & N & Mean & Std. Deviation \\
\hline Motivation & Age & & & \\
& 30 or younger & 5 & 27.20 & 4.76 \\
Intrinsic Motivation & $31-40$ & 47 & 24.85 & 4.58 \\
& 41 or older & 29 & 25.24 & 3.89 \\
& 30 or younger & 5 & 51.40 & 7.92 \\
Extrinsic Motivation & $31-40$ & 46 & 45.65 & 6.22 \\
& 41 or older & 28 & 43.64 & 7.11 \\
Overall Motivation & 30 or younger & 5 & 78.60 & 12.42 \\
& $31-40$ & 46 & 70.70 & 9.98 \\
& 41 or older & 27 & 68.59 & 9.81 \\
\hline
\end{tabular}

Table 5 shows Chinese visiting scholars' intrinsic motivations and extrinsic motivation based on their highest degree. It appeared that scholars with a master's degree or bachelor's degree tended to have more intrinsic and extrinsic motivations compared with those who have a doctorate. 
Table 5. Motivation Differences based on Highest Degree.

\begin{tabular}{llll}
\hline Motivation Degree & N & Mean & Std. Deviation \\
\hline Master or Below & 29 & 26.62 & 3.15 \\
Intrinsic Motivation & & & \\
Doctor & 52 & 24.31 & 4.72 \\
Master or Below & 29 & 47.10 & 4.88 \\
Extrinsic Motivation & & & \\
Doctor & 50 & 44.26 & 7.58 \\
Master or Below & 28 & 73.61 & 6.97 \\
Overall Motivation & & & \\
Doctor & 50 & 68.72 & 11.33 \\
\hline
\end{tabular}

Table 6 shows Chinese visiting scholars' intrinsic and extrinsic motivation based on their professional rank. It appeared that lecturers tended to have more intrinsic and extrinsic motivation. However, their extrinsic motivation was very similar regardless of their professional ranks.

Table 6. Motivation Differences based on Professional Rank.

\begin{tabular}{llll}
\hline Motivation Professional Rank & N & Mean & Std. Deviation \\
\hline Lecturer & 24 & 26.25 & 3.35 \\
Associate Professor & 39 & 24.87 & 4.21 \\
Intrinsic Motivation & & & \\
Professor & 13 & 25.69 & 3.95 \\
Other & 5 & 20.40 & 7.73 \\
Lecturer & 24 & 45.79 & 6.76 \\
Associate Professor & 38 & 45.63 & 5.59 \\
Extrinsic Motivation & & & \\
Professor & 12 & 45.08 & 8.61 \\
Other & 5 & 41.00 & 11.20 \\
Lecturer & 24 & 72.04 & 9.19 \\
Associate Professor & 37 & 70.70 & 8.51 \\
Overall Motivation & & & \\
Professor & 12 & 70.42 & 12.05 \\
Other & 5 & 61.40 & 18.77 \\
\hline
\end{tabular}

Although Chinese visiting scholars seemed to report different motivation based on their demographic background information, we continued to investigate whether these demographic variables could predict their motivation for participating in extra-curricular oral English study. Results from the multiple regression analysis suggests a statistically significant association between overall motivation and the independent variables, $\mathrm{F}(72,5)=2.61, p=.032$. We also computed the effect size $\mathrm{R}^{2}$ to be.154, which indicates that $15.4 \%$ of the variation in students' motivation could be explained by the predictors. Scholars' major and highest degree were identified as the significant predictors of their overall motivation. However, their gender, age, and professional ranks were not significant predictors of their motivations.

Table 7. Multiple Regression (Overall Motivation is the dependent variable).

\begin{tabular}{llllll}
\hline Model & \multicolumn{2}{l}{$\begin{array}{l}\text { Unstandardized } \\
\text { Coefficients }\end{array}$} & $\begin{array}{l}\text { Standardized } \\
\text { Coefficients }\end{array}$ & t & Sig. \\
\hline & B & Std. Error & Beta & & \\
\hline & 84.16 & 9.20 & & 9.15 & .00 \\
(Constant) Gender & -1.14 & 2.41 & -.05 & -.47 & .64 \\
Major Age & 7.52 & 3.35 & .30 & 2.25 & .03 \\
Highest Degree & -2.30 & 2.02 & -.13 & -1.14 & .26 \\
Professional Rank & -5.73 & 2.80 & -.27 & -2.05 & .04 \\
& -2.49 & 1.48 & -.21 & -1.69 & .10 \\
\hline
\end{tabular}

We did find a significant association between scholars' intrinsic motivation and their extrinsic motivation. The Pearson correlation coefficient was.67, which is significant at the 0.01 level. It suggests that the scholars who have stronger intrinsic motivation tended to have stronger extrinsic motivation.

In order to better understand different motivations of the Chinese visiting scholars, the second part of survey also contained open-ended questions. In the qualitative analysis, we found that the first question explored the main reasons why they spontaneously attended the extra- curricular oral English class. The majority of respondents (60.6\%) demonstrated that they hoped to communicate fluently with foreign professors and experts to ultimately improve their academic level. It is this self-determined extrinsic motivation that positively influenced and motivated them to persevere in this activity, which especially based on external instrumental motivation. A smaller number of respondents (28.2\%) stated their reason for studying English was in hopes of improving or perfecting their spoken English because of interest in the language (intrinsic motivation).

In describing their perceptions of oral English gains from attending the extra-curricular oral English class, more than half of the respondents $(55.5 \%)$ said they gained a lot, much more than they expected. To be specific, they made more friends (25.4\%) and learned more local culture (22.2\%). They also said the extra-curricular study enhanced their communication $(25.4 \%)$. The result of this question is nearly congruent with the results of the Likert scale questions (Table 1). However, it is worth mentioning that a small number, five out of sixty-three people $(7.9 \%)$ thought they gained little because of the short duration of their participation in their extra- curricular English class, which was either very informal or entry level.

\section{Conclusion}

This study of eighty-two Chinese visiting scholars across the USA revealed a group of academics who voluntarily attended extra-curricular English classes. They did so mainly to better communicate with their English-speaking colleagues, mentors, and experts in their academic field. Studying in the USA affords an opportunity to expand one's knowledge within a field of study while immersing oneself in American culture and the English language. This phenomenon arose after the Mao era when China encouraged scholars to study abroad to obtain current information in their fields of study. This effort continues to be funded by the Chinese government and administered through individual Chinese colleges and universities. Recently, this phenomenon has spread beyond universities and includes professionals from industry and other sectors. Visiting scholars also may bring their spouses or children with them[15].

During their time in the USA, visiting scholars may attend lectures and classes, engage in research with their sponsor, provide lectures, engage with the local community, and visit destinations of interest within the USA. Some may choose to 
continue their English study in informal or community settings. The results of our survey indicate that such study is motivated by a desire to improve professionally and to take further advantage of the visiting scholar's time in the USA. Further English study allowed the visiting scholars to better communicate with their colleagues within the university setting. Intentional language study provided added opportunities to converse with others during the English class. This helped them to improve their ability to listen and speak.

The demands for English competence in study and work required ongoing English development. The motivation to study English arose from this perceived need, thus studying English was seen as important to the visiting scholars' career goals. Their decision to study English was autonomous and self-determined, indicating introjected regulation, a highly internalized type of external motivation. Given the requirements and qualification criteria for becoming a visiting scholar, pressure to produce research, and engage productively with American colleagues, visiting scholars are extremely motivated, but at an autonomous level.

Although most respondents were concerned with the demands of work and study, a fair number of them were also intrinsically motivated by a desire to engage in social life, make friends, and learn about American culture. Studying English within an informal, community- based context provides visiting scholars with a social outlet. The international make-up of community English classes provided a community of people with the common experience of being visitors to a foreign country. Within this context, visiting scholars could obtain valuable information about transportation for shopping, activities for their children, or acquiring roommates for an improved housing situation. The community-based English classes also provided opportunities to make friends with whom they might share meals, shop, or explore the community. Attending English class therefore involved intrinsic motivation for some respondents. The coexistence of socialization and study/work aspects of motivation can be seen as positive motivating factors [16]. It was important to continue studying English because of the pressures of work, but also for the pleasures of social activity.

The results of this study have implications for university and community planning for international visiting scholars. It is common practice for universities to assist visitors with visa and housing information. Office space and a computer may also be provided by the department. However, the language and social needs of visitors must also be considered. Even though Chinese scholars must pass a language test to qualify for the visiting scholar program, individuals may feel the need for continuing English language development once they arrive in the USA. By directing the visitors to informal community or university-based classes, the visitor will be provided not only with language development, but also essential social and cultural experiences. Informal English classes allow for additional, low-risk opportunities to converse with others in English. A low-risk environment for English development is provided through no- cost or low- cost classes that are not credit-bearing. Churches and volunteer organizations provide such classes in many university communities. Conversation partner programs match international university students with native English speaker volunteers. Such programs have potential for visiting scholars, however, some of the benefits of socializing with a larger group of internationals might be missing from the conversation partner dynamic. As universities continue to invite international visiting scholars to their campuses, opportunities for continued English development should be explored within existing university programs as well as through community resources.

\section{Acknowledgements}

We are grateful to get the help of Fund project: Shanxi Scholarship Council of China (Project No. 2020-155) Title: Research on the development path of Shanxi vocational education internationalization driven by the construction of "Double High Plan".

\section{References}

[1] Xue, M., Chao, X., \& Kuntz, A. M. (2015). Chinese visiting scholars' academic socialization in US institutions of higher education: A qualitative study. Asia Pacific Journal of Education, 35: 2, 290-307.

[2] Altbach, P. G. (1989). The new internationalism: Foreign students and scholars. Studies in Higher Education, 14: 2, 125-136.

[3] Age-related differences in motivation in learning English among mainland Chinese students. International Journal of Applied Linguistics, Vol. 25, No. 1, 67-81.

[4] Ryan, R. M., \& Deci, E. L. (2000). Intrinsic and extrinsic motivations: Classic definitions and new directions. Contemporary Educational Psychology, 25, 54-67.

[5] Deci, E. L., \& Ryan, R. M. (1985a). Intrinsic motivation and self-determination in human behavior. New York, Plenum.

[6] Deci, E. L., \& Ryan, R. M. (1985b). The General causality orientations scale: Self-determination in personality. Journal of Research in Personality, 19, 109-134.

[7] Gulbinskienè, D., \& Dubovičienè, T. (2015). Language learning motivation of EFL students at LEU. Foreign Languages, Vol. 17, No. 3, 137-145.

[8] Kember, D. (2008). Characterizing the motivational orientation of students in higher education: A naturalistic study in three Hong Kong universities. British Journal of Educational Psychology, 78, 313-329.

[9] A. H. (2017). Sixty years of language motivation research: Looking back and looking forward. Sage Open, JanuaryMarch, 1-11.

[10] Semaan, G., \& Yamazaki, K. (2015). The relationship between global competence and language learning motivation: An empirical study in critical language classrooms. Foreign Language Annals, 511-520. 
[11] Weger, H. D. (2013). Examining English language learning motivation of adult international learners studying abroad in the US. RELC Journal, 44 (1), 87-101.

[12] Yuan, W. (2011). Academic and cultural experiences of Chinese students at an American university: A qualitative study. Intercultural Communication Studies, 2 0(1), 141-157.

[13] Wang, C., \& Zuo, H. (2014). Understanding Chinese international students' difficulties and strategies in learning English for academic purposes. In W. Ma \& C. Wang (Eds.), Learner' privilege and responsibility: A critical examination of the experiences and perspectives of learners from Chinese backgrounds in the United States. Charlotte, NC: Information Age Publishing, 67-82.

[14] Larrota, C. (2009). Final thoughts on community in adult ESL. New Directions for Adult and Continuing Education, 121, 7577.

[15] Zhao, X. (2015, June 27). Visiting scholars now come from many fields. China Daily.

[16] Kormos, K., \& Csizér, J. (2008). Age-related differences in the motivation of learning English as a foreign language: Attitudes, selves, and motivated learning behavior. Language Learning, 58.2: 327-55. 